\title{
Diffusion Controlled Extended Release Dosage Form
}

National Cancer Institute

\section{Source}

National Cancer Institute. Diffusion Controlled Extended Release Dosage Form. NCI

Thesaurus. Code C42740.

A solid, semi-solid, solution or suspension covered with an outer permeable polymeric membrane designed to release active and/or inert ingredient(s) at a controlled, prolonged rate so as to reduce dosing frequency. Water permeates through the membrane to the core to dissolve the ing redient(s) which subsequently exit the membrane at a rate determined by their solubility and the thickness and porosity of the membrane. 